\title{
Investigation of the Phase Stabilities in AlNiCoCrFe High Entropy Alloys
}

\author{
Todd M. Butler ${ }^{1,2, *}$ and Mark L. Weaver ${ }^{2}$ \\ ${ }^{1}$ UES, Inc., 4401 Dayton-Xenia Road, Dayton, OH 45432, USA
}

${ }^{2}$ Department of Metallurgical and Materials Engineering, University of Alabama, Tuscaloosa, AL, 35487-0202, USA

* Corresponding author

Keywords: high-entropy, CALPHAD

\begin{abstract}
High-entropy alloys (HEAs) are a developing class of materials that show great potential for a variety of commercial structural and coating applications, particularly where heat and corrosion resistance are desired. In these types of applications, the relative phase stabilities play a crucial role, since they influence the material design process and expected component lifetimes. However, a satisfactory understanding of the phase stabilities in HEAs and the ability to thermodynamically predict their behaviors is limited. This study methodically couples analytical characterization techniques with predictions based on CALPHAD models to investigate the phase equilibria and phase stabilities of a series of AlNiCoCrFe based HEAs. Heat treatments were conducted at $700^{\circ} \mathrm{C}$ for 1000 hours and $1050^{\circ} \mathrm{C}$ for 520 hours, followed by water quenching, to ensure adequate time for metastable equilibrium to be achieved. The accuracy and merit of the thermodynamic simulations in predicting the stable phases and their respective chemistries is discussed relative to the experimental observations.
\end{abstract}

\section{Introduction}

Traditional alloy development strategies typically involve the study of a major constituent element with minor alloying additions to form suitable microstructures with specific properties (i.e., Ti alloys, Superalloys, etc) [1,2]. With regard to phase diagrams, these types of alloys 
generally reside near the corners, leaving the central phase regions relatively unexplored [3]. However, an alternative alloy development approach examining equiatomic and near equiatomic composition space has emerged, producing a novel class of materials termed high-entropy alloys (HEAs) [2-6]. Due to their complex chemistries, HEAs inherently exhibit high ideal configurational entropies of mixing that have been proposed to aid in the retention of highsymmetry, disordered FCC and/or BCC solid solution phases [3,4,7,8]. However, in many cases, these solid solution phases are often accompanied by the formation of ordered intermetallic phases (i.e. B2 and sigma) [9-13]. HEAs have been reported to exhibit a variety of unique properties including enhanced mechanical strength, at both ambient and elevated temperatures [9-11,14-16] and resistance in oxidizing/corrosive environments [9,17-30]. These attributes, amongst others, make them ideal candidates as materials for use in high temperature environments.

The direct implementation of HEAs is hindered by the lack of a fundamental understanding of their high temperature phase stabilities and effective models to predict their behaviors. Thus, additional high-quality, analytical characterization of heat treated HEAs, coupled with computational modeling is vital for future commercial development. There have been various attempts to validate existing models/databases by correlating experimental results with those derived computationally. These modeling attempts include comparisons with empirically determined rules, termed the HEA phase formation rules [8,12-14,31-40], ab-initio based methods [41-47], and thermodynamic calculations based on the CALPHAD (CALculation of PHAse Diagrams) method [36,48-53]. The CALPHAD method has evolved over the past 30 years and has become widely utilized in the scientific community due to its simplicity, computational efficiency, and reasonable agreement with experimental data [36,50,51]. This method correlates a predicted equilibrium state to an overall minimum Gibbs free energy in the system. Calculations 
conducted in four to six element space are evaluated using extrapolations of experimentally backed binary, ternary, and in some cases quaternary systems [51]. Thus, the accuracy of the resulting predictions is often highly dependent upon the thermodynamic database used and needs to be experimentally validated.

The aim of this work is to fundamentally investigate the high temperature phases in a series of heat treated AlNiCoCrFe based HEAs and evaluate the accuracy of CALPHAD based predictions using ThermoCalc ${ }^{\mathrm{TM}}$ [54]. This particular system is ideal for this fundamental phase study since it is one of the most thoroughly investigated HEA systems [11,15,16,29,38,50,55-61]. However, there is currently a lack of published literature examining the phase equilibria at elevated temperatures and little known about the relative phase stabilities over long periods of time. The equilibrium predictions presented in this work were determined using extrapolations from

experimentally assessed binary and ternary systems found in the TCNI8 (ThermoCalc ${ }^{\mathrm{TM}}$, Ni-based superalloys) database [62]. Collectively, these results will provide a systematic assessment of the high temperature phase stabilities of AlNiCoCrFe HEAs. Additionally, this work will help to elucidate the accuracy and usefulness of CALPHAD based models for predicting the phase equilibria of compositionally complex alloys.

\section{Experimental Procedures}

Four bulk alloys with nominal compositions (at.\%) of $\mathrm{Al}_{10} \mathrm{Ni}_{22.5} \mathrm{Cr}_{22.5} \mathrm{Co}_{22.5} \mathrm{Fe}_{22.5}$, $\mathrm{Al}_{15} \mathrm{Ni}_{21.25} \mathrm{Cr}_{21.25} \mathrm{Co}_{21.25} \mathrm{Fe}_{21.25}, \mathrm{Al}_{20} \mathrm{Ni}_{20} \mathrm{Cr}_{20} \mathrm{Co}_{20} \mathrm{Fe}_{20}$, and $\mathrm{Al}_{30} \mathrm{Ni}_{17.5} \mathrm{Cr}_{17.5} \mathrm{Co}_{17.5} \mathrm{Fe}_{17.5}$ (designated: $\mathrm{Al}_{10}, \mathrm{Al}_{15}, \mathrm{Al}_{20}$, and $\mathrm{Al}_{30}$ ) were arc-melted into buttons from high purity elemental constituents on a water-cooled copper hearth. This process was done under an ultra-high purity (UHP) argon atmosphere. Each button was flipped and re-melted a total of five times to promote uniformity. 
The experimental bulk compositions, as measured via energy-dispersive x-ray spectroscopy (EDS) in a transmission electron microscope, are shown in Table 1.

Prior to annealing, specimens were sectioned from the as-cast buttons and encapsulated in quartz tubes that were partially backfilled with UHP argon. Two separate annealing treatments were performed, one at $700^{\circ} \mathrm{C}$ for 1000 hours and another at $1050^{\circ} \mathrm{C}$ for 520 hours, followed by water quenching. The quartz tubes were broken during quenching to achieve faster cooling rates in the actual specimens. A full microstructural analysis was conducted on each annealed specimen using a combination of x-ray diffraction (XRD), scanning electron microscopy (SEM), transmission electron microscopy (TEM), and EDS. Backscattered electron (BSE) images were captured on a JEOL 7000F SEM. XRD data was collected on a Philips X'pert MPD XRD with $\mathrm{Cu}-\mathrm{K} \alpha$ radiation at $45 \mathrm{kV}$ and $40 \mathrm{~mA}$. Scans were conducted at a rate of 0.1 degrees per minute. All TEM specimens were prepared using a variation of the focused-ion-beam (FIB) in-situ lift-out technique in an FEI Quanta 200 3D Dual Beam FIB-SEM [63]. High angle annular dark field images (HAADF) and selected area diffraction patterns (SADPs) were captured on a 200-KeV FEI Tecnai $\mathrm{G}^{2}$ F-20 Supertwin scanning-transmission electron microscope (S)TEM. TEM-EDS data was evaluated using FEI ES Vision software with an applied thickness correction [64]. In this paper, the high temperature phase equilibria were modeled by means of the CALPHAD method using ThermoCalc ${ }^{\mathrm{TM}}$ and the TCNI8 database [54,62]. For comparative purposes, the phase equilibria were also modeled using the TCFE8 and TCHEA1 databases $[65,66]$. As has been noted by Zhang and Kattner [67], the design of alloys consisting of multiple principal elements requires thermodynamic database that include accurate and full thermodynamic descriptions of all of the constituent systems. The TCHEA1 database, which is actually a subset of the TCNI8 database, yielded results that were identical to those obtained using the TCNI8 database. The TCFE8 
database, which was designed for alloys containing a minimum of $50 \mathrm{wt} \% \mathrm{Fe}$, was found to yield inaccurate results. In this paper, all calculations were based on the experimentally determined alloy compositions.

\section{Results and Discussion}

\subsection{Microstructures and Modeling of $\mathrm{Al}_{10} \mathrm{Ni}_{22.5} \mathrm{Cr}_{22.5} \mathrm{Co}_{22.5} \mathrm{Fe}_{22.5}$}

Figs. 1(a) and (b) show representative backscattered electron (BSE) images of the annealed $\mathrm{Al}_{10} \mathrm{HEA}$. After annealing at $700^{\circ} \mathrm{C}$ for 1000 hours, the microstructure consisted of low atomic number $(Z)$ contrast regions, labeled ID, that were dispersed in a high-Z contrast matrix, labeled D (Fig. 1(a)). Based upon our previous analysis of as-cast alloys [24,68,69], these ID regions are believed to be remnants of the original solidification microstructure. The high- $\mathrm{Z}$ matrix phase was found to contain a high distribution of low-Z precipitates with plate-like morphologies (see the inset image in Fig. 1(a)). Similarly, the ID regions consisted of a continuous low-Z matrix with high-Z precipitates of varying sizes and morphologies. Annealing at $1050^{\circ} \mathrm{C}$ for 520 hours resulted in a coarser microstructure where the low-Z precipitates in region $\mathrm{D}$ coarsened into several variants. The ID regions also coarsened but were found to be precipitate free, as is evident from the inset BSE image in Fig. 1(b).

The crystal structures and chemistries of the observed phases were investigated using a combination of XRD and TEM. The XRD spectra for both annealing treatments are shown in Fig. 1(c). At $700^{\circ} \mathrm{C}$, the spectrum only contained peaks associated with $\mathrm{BCC}$ and/or B2 phases (aBCC

$\approx \mathrm{aB} 2 \approx 2.88 \AA$ ). In contrast, the $1050^{\circ} \mathrm{C}$ spectrum contained peaks associated with $\mathrm{BCC}$ and/or $\mathrm{B} 2\left(\mathrm{aBCC} \approx \mathrm{aB}_{2} \approx 2.88 \AA\right.$ ) , and FCC (aFCC $\approx 3.58 \AA$ ) phases. Fig. 2 shows STEM-HAADF images and SADPs from the $700^{\circ} \mathrm{C}$ and $1050^{\circ} \mathrm{C}$ annealed $\mathrm{Al}_{10} \mathrm{HEAs}$. In addition to the $\mathrm{BCC}$ and/or $\mathrm{B} 2$ phases derived from $\mathrm{XRD}$ experiments, the $\mathrm{Al}_{10} \mathrm{HEA}$ annealed at $700^{\circ} \mathrm{C}$ was found to contain 
FCC and sigma phases, Fig. 2 (a)-(e). The ID regions consisted of a Ni+Al-rich B2 matrix with high-Z contrast FCC precipitates that were rich in Co and $\mathrm{Cr}$ (Fig. 2 (b) and Table 2). In between the ID and D regions, a homogeneous, Cr-rich sigma phase was observed, Fig. 2 (c). The dominant matrix phase exhibited an FCC structure and contained a high density of Ni+Al-rich B2 precipitates, Fig. 2 (e). The $\mathrm{Al}_{10} \mathrm{HEA}$ annealed at $1050^{\circ} \mathrm{C}$ was found to consist of a homogeneous, high-Z, FCC matrix, along with coarse but homogeneous low-Z regions with B2 crystal structures, Fig. 2 (f)-(i). The FCC matrix was rich in $\mathrm{Co}, \mathrm{Cr}$, and $\mathrm{Fe}$, while the $\mathrm{B} 2$ regions contained high amounts of $\mathrm{Ni}$ and $\mathrm{Al}$, as shown in Table 2.

The experimental phase observations derived from SEM, XRD, and TEM analyses were compared with those predicted via CALPHAD based thermodynamic modeling. Fig. 1 (d) shows the calculated phase fractions as a function of temperature for the $\mathrm{Al}_{10} \mathrm{HEA}$ with the $700^{\circ} \mathrm{C}$ and $1050^{\circ} \mathrm{C}$ isotherms identified with vertical markers. At $1050^{\circ} \mathrm{C}$, a combination of $\sim 80 \%$ FCC and $\sim 20 \%$ B2 phases are predicted, which is consistent with the experimental results, Fig. 2 (f)-(i). At $700^{\circ} \mathrm{C}$, the model predicts a combination of $\sim 45 \% \mathrm{~B} 2, \sim 35 \% \mathrm{FCC}$, and $\sim 20 \%$ sigma phases. This also correlates well to the experimental findings, Fig. 2 (a)-(e). CALPHAD based models were also used to predict the relative chemistries of the phases predicted at $700^{\circ} \mathrm{C}$ and $1050^{\circ} \mathrm{C}$, as shown in Table 2. With the exception of the B2 phases, the predicted chemistries for each phase were comparable to the TEM-EDS results. To quantify the differences between the predicted chemistries and the experimental results, the average atomic percent difference between each element in a given phase, neglecting reported errors, are also reported in Table 2. On average, the predicted chemistries are at most $\sim 8.3$ at. $\%$ different and most fall below 2 at. $\%$ different than experimental values.

\subsection{Microstructures and Modeling of $\mathrm{Al}_{15} \mathrm{Ni}_{21.25} \mathrm{Cr}_{21.25} \mathrm{Co}_{21.25} \mathrm{Fe}_{21.25}$}


Representative BSE images for the annealed $\mathrm{Al}_{15}$ HEA are shown in Figs. 3(a) and (b). Annealing at $700^{\circ} \mathrm{C}$ for 1000 hours promoted the formation of a modulating net-like structure, consisting of interpenetrating high- $Z$ and low- $Z$ phases, Fig. 3(a). The microstructure was coarse in some regions, although the phase distribution and morphologies remained similar to the finer regions. Additionally, a nano-scale high- $\mathrm{Z}$ phase was detected in the low- $\mathrm{Z}$ regions, as labeled with an arrow in the inset high magnification image in Fig. 3(a). Comparable to the $\mathrm{Al}_{10} \mathrm{HEA}$, annealing of the $\mathrm{Al}_{15} \mathrm{HEA}$ at $1050^{\circ} \mathrm{C}$ for 520 hours produced a heavily coarsened microstructure, consisting of a high- $Z$ phase encompassing a low- $Z$ regions, Fig. 3(b). The high- $Z$ phase was homogeneous, while the low- $\mathrm{Z}$ regions contained fine-scale, high- $\mathrm{Z}$ precipitates in a low- $\mathrm{Z}$ matrix (see the inset high magnification BSE image in Fig. 3(b)).

Fig. 3(c) shows XRD spectra from the annealed alloys. At $700^{\circ} \mathrm{C}$, the spectrum exhibits peaks associated with FCC ( $\left.\mathrm{a}_{\mathrm{FCC}} \approx 3.59 \AA\right), \mathrm{BCC} / \mathrm{B} 2(\mathrm{a} \approx 2.88 \AA)$, and sigma phases $\left(\mathrm{a}_{\sigma} \approx 8.8 \AA\right.$, $\mathrm{c}_{\sigma} \approx 4.54 \AA$ ). Interestingly, at $1050^{\circ} \mathrm{C}$, the sigma phase is suppressed and the spectrum only contains peaks correlating to $\mathrm{FCC}(\mathrm{aFCC} \approx 3.59 \AA)$, and $\mathrm{BCC} / \mathrm{B} 2(\mathrm{a} \approx 2.88 \AA$ phases. The phases were then examined using TEM, as shown by the STEM-HAADF images and SADPs in Fig. 4. As was shown in the $\mathrm{XRD}$ results, the $700^{\circ} \mathrm{C} \mathrm{Al}_{15}$ HEA consisted of a low-Z, B2 matrix phase, along with FCC and sigma phases, Fig. 4 (a)-(d). Similar to the $\mathrm{Al}_{10} \mathrm{HEA}$, the $\mathrm{B} 2$ regions were enriched in $\mathrm{Ni}$ and $\mathrm{Al}$, while the $\mathrm{FCC}$ regions contained high concentrations of $\mathrm{Co}, \mathrm{Cr}$, and $\mathrm{Fe}$, Table 3. As expected, the sigma phase displayed a high concentration of $\mathrm{Cr}$ and was nearly depleted of $\mathrm{Al}$. In agreement with the XRD results, the $\mathrm{Al} 15 \mathrm{HEA}$ annealed at $1050^{\circ} \mathrm{C}$ did not contain the sigma phase and consisted of high-Z, FCC regions enriched in $\mathrm{Co}, \mathrm{Cr}$, and $\mathrm{Fe}$, along with low-Z B2 regions enriched in Ni and Al, Fig. 4 (e)-(h). Contrast variations indicative of nanoscale precipitation were observed within the $\mathrm{B} 2$ regions. We were unable to quantitatively identify 
these precipitates chemically or structurally due to their small size and morphology. However, a comparison of these results to those of Wang et al. [11,56,61] on similar alloys, suggests that these precipitates likely exhibit BCC structures. This is also supported experimentally by the observation of the primary B2 zone axes (i.e. $\langle 100\rangle,\langle 110\rangle$, and $\langle 111\rangle$ ), which reveals a strong epitaxial relationship between the matrix and precipitate, with perfect overlapping in the electron diffraction spots.

Fig. 3 (d) shows the calculated phase fractions as a function of temperature for the $\mathrm{Al}_{15}$ HEA. At $1050^{\circ} \mathrm{C}$, the model accurately predicts a combination of $\mathrm{FCC}$ and $\mathrm{B} 2$ phases. At $700^{\circ} \mathrm{C}$, the model predicts the B2 and sigma phases, but does not accurately predict the experimentally observed FCC phase. The predicted phase chemistries are also shown in Table 3, along with those determined by TEM-EDS. On average, the predicted chemistries were fairly consistent and differed at most by $\sim 4.7$ at. $\%$. However, the model did not accurately predict the stability, and therefore the chemistry of the FCC phase.

\subsection{Microstructures and Modeling of $\mathrm{Al}_{20 \mathrm{Ni}} \mathrm{Cr}_{20} \mathrm{Co} \mathrm{COFe}_{20}$}

Figs. 5(a) and (b) show representative BSE images of the annealed $\mathrm{Al}_{20} \mathrm{HEA}$. Annealing at $700^{\circ} \mathrm{C}$ for 1000 hours resulted in a complex distribution of phases, Fig. 5(a). The microstructure exhibited highly transformed, low-Z regions enriched in $\mathrm{Ni}$ and $\mathrm{Al}$ (labeled $\mathrm{Ni}+\mathrm{Al}$ rich), along with coarser, high-Z surrounding regions enriched in $\mathrm{Co}, \mathrm{Cr}$, and $\mathrm{Fe}$. The high-Z regions displayed a combination of high-Z precipitates in a low-Z matrix. Similarly, the highly transformed regions contained a fine-scale distribution of high- $Z$ cuboidal precipitates in a low- $Z$ matrix, as evident from the inset high magnification BSE image in Fig. 5(a). A plate-like, high-Z phase was observed near the boundaries of the highly transformed region, as indicated by arrows in the inset image in Fig. 5(a). Annealing at $1050^{\circ} \mathrm{C}$ for 520 hours promoted a coarse distribution of high-Z phases in 
a Ni+Al-rich, low-Z matrix, Fig. 5(b). A semi-continuous, high-Z phase was observed along grain boundaries and within individual grains. Some of the high- $\mathrm{Z}$ phase within the individual grains contained low-Z precipitates, as indicated by the arrow in the inset BSE image in Fig. 5(b). The $\mathrm{Ni}+\mathrm{Al}$-rich matrix was also observed to have a uniform distribution of high-Z, nanoscale precipitates.

At $700^{\circ} \mathrm{C}$, the XRD spectrum contained peaks associated with $\mathrm{FCC}(\mathrm{aFCC} \approx 3.60 \AA$ ), $\mathrm{BCC} / \mathrm{B} 2(\mathrm{a} \approx 2.89 \AA)$, and sigma phases $\left(\mathrm{a}_{\sigma} \approx 8.80 \AA \mathrm{c}_{\sigma} \approx 4.54 \AA\right)$, Fig. 5(c). However, at $1050^{\circ} \mathrm{C}$ the XRD spectrum only exhibited peaks associated with FCC (aFCC $\approx 3.60 \AA$ ), BCC and/or B2 ( $\mathrm{aBCC} \approx \mathrm{aB} 2 \approx 2.89 \AA$ A) phases. These observations are similar to those of Tang et al. [15] on a HIPed and homogenized, equimolar AlCoCrFeNi HEA. The phases were further investigated using TEM, as shown by the STEM-HAADF images and SADPs in Fig. 6. The $700^{\circ} \mathrm{C} \mathrm{Al}_{20} \mathrm{HEA}$ contained a combination of FCC, B2, BCC, and sigma phases, Fig. 6 (a)-(e). The highly transformed region (labeled B2 $+\mathrm{BCC}$ ) exhibited a Ni+Al-rich B2 matrix with coherent, $\mathrm{Cr}$-rich BCC precipitates, Table 4. The coarser regions consisted of a B2 matrix with a discontinuous, Co, Cr, and Fe rich FCC phase. As observed via SEM, Fig. 5 (b), plate-like, sigma phase precipitates were found near the boundaries of the highly transformed B2 + BCC regions, Fig. 6 (a) and (e). This sigma phase was extensively rich in $\mathrm{Cr}$ and $\mathrm{Fe}$, as shown in Table 4. In contrast, the sigma phase was not observed in the $1050^{\circ} \mathrm{C} \mathrm{Al}_{20} \mathrm{HEA}$ and the microstructure consisted of $\mathrm{FCC}, \mathrm{B} 2$, and BCC phases, Fig. 6 (f)-(i). The grain boundaries were found to be populated by a continuous, Co, Cr, and Fe rich FCC phase, Fig. 6 (i). The FCC phase was found to be bordered by a Ni+Al-rich B2 matrix, containing nano-scale precipitates. Similar to the $\mathrm{Al}_{15} \mathrm{HEA}$, these precipitates are likely to be BCC since they share a strong epitaxy with the B2 matrix and perfectly overlap in the SADPs. Additionally, medium- $Z$ contrast regions (labeled BCC + B2) were observed and 
exhibited BCC crystal structures, Fig. 6 (g). These BCC regions also contained Ni+Al-rich B2 precipitates. Differentiation of the BCC matrix and B2 precipitate structures were determined by observing the $\langle 001\rangle_{\mathbf{B} 2} / /\langle 001\rangle_{\mathbf{B C C}}$ and $\left.\langle 011\rangle_{\mathbf{B} 2} / /<011\right\rangle_{\mathbf{B C C}}$ SADPs. Diffraction patterns taken near precipitates displayed distinct superlattice reflections consistent with a B2 structure, Fig. 6 (h). Likewise, patterns captured in precipitate free regions contained no superlattice reflections, Fig. $6(\mathrm{~g})$. Therefore, the matrix phase is inherently BCC while the precipitates exhibit B2 structures.

The calculated phase fractions as a function of temperature for the $\mathrm{Al}_{20} \mathrm{HEA}$ is shown in Fig. 5 (d). The model predicts a combination of BCC and B2 phases at $1050^{\circ} \mathrm{C}$. This is only semiconsistent with the experimental results, since an additional FCC phase was observed along the grain boundaries. At $700^{\circ} \mathrm{C}$, only B2 and sigma phases are predicted by the model. This is vastly different than the experimental observations, where additional FCC and BCC phases were found. However, the calculated chemistries of the phases that the model did predict were found to correlate with experimental TEM-EDS. Quantitatively, the average atomic percent difference between elements in each phase was found to be no more than $\sim 5.2$ at. $\%$.

\subsection{Microstructures and Modeling of $\mathrm{Al}_{30} \mathrm{Ni}_{17.5} \mathrm{Cr}_{17.5} \mathrm{Co}_{17.5} \mathrm{Fe}_{17.5}$}

Figs. 7(a) and (b) show representative BSE images of the annealed $\mathrm{Al}_{30}$ HEAs. Annealing at $700^{\circ} \mathrm{C}$ for 1000 hours did not appear to coarsen the microstructure, which consisted of a low-Z matrix with a nano-scale distribution of high-Z precipitates, Fig. 7(a). This high-Z phase was also found to populate along the grain boundaries, as indicated with arrow in the inset image of Fig. 7 (a). Annealing at $1050^{\circ} \mathrm{C}$ for 520 hours significantly coarsened the microstructure, Fig. 7(b). Similar to the $700^{\circ} \mathrm{C}$ treatment, the microstructure consisted of a low-Z matrix with coarse high- $\mathrm{Z}$ precipitates. The high-Z phase along the grain boundaries appeared to dissolve at the expense of 
the growth of surrounding high-Z precipitates. Higher magnification imaging revealed that the low- $Z$ matrix contained fine-scale high- $Z$ precipitates, and the high- $Z$ phase contained low- $Z$ precipitates, as evident from the inset BSE image in Fig. 7(b).

In order to determine the phase structures and chemistries, XRD and TEM techniques were also conducted on the annealed $\mathrm{Al}_{30} \mathrm{HEAs}$. At $700^{\circ} \mathrm{C}$, the $\mathrm{XRD}$ spectrum displayed peaks associated with $\mathrm{BCC}(\mathrm{aBCC} \approx 2.88 \AA)$ and/or $\mathrm{B} 2\left(\mathrm{a}_{\mathrm{B} 2} \approx 2.88 \AA\right)$ phases, Fig. 7(c). This was the same for $1050^{\circ} \mathrm{C}$; however, some indistinguishable peak broadening around $43^{\circ} 2 \theta$ was observed. The annealed alloys were then investigated using TEM, as shown by the STEM-HAADF images and SAPDs in Fig. 8. Similar to the $\mathrm{B} 2+\mathrm{BCC}$ regions in the $\mathrm{Al}_{20} \mathrm{HEA}$, Fig. 6 (a), the $700^{\circ} \mathrm{C} \mathrm{Al}_{30}$ HEA consisted entirely of a Ni+Al-rich B2 matrix, with Cr-rich BCC precipitates, Fig. 8 (a)-(d) and Table 5. The structures of the matrix and precipitate were inferred from the same methodology used for the phase determinations in the $\mathrm{Al}_{15}$ HEA. This precipitate / matrix relationship is also consistent with those determined in the work of Wang et al. on similar HEAs $[11,56,61]$. The $1050^{\circ} \mathrm{C} \mathrm{Al} 30 \mathrm{HEA}$ contained a mixture of $\mathrm{Ni}+\mathrm{Al}$-rich $\mathrm{B} 2$ regions with $\mathrm{BCC}$ precipitates and $\mathrm{Cr}$ rich, BCC regions exhibiting B2 precipitates, Fig. 8 (e)-(i).

The thermodynamically calculated phase diagram for the $\mathrm{Al}_{30}$ HEA is depicted in Fig. 7 (d). Unlike all of the other simulations, no sigma phase was predicted to be stable for this alloy between $200^{\circ} \mathrm{C}$ to $1500^{\circ} \mathrm{C}$. At both $1050^{\circ} \mathrm{C}$ and $700^{\circ} \mathrm{C}$, the model predicts a combination of $\mathrm{B} 2$ and BCC phases, with a slightly higher fraction of B2 phase at the higher temperature. These predictions are in agreement with the experimentally determined phases, Fig. 8. The calculated phase chemistries were also found to correlate with those determined via TEM-EDS, Table 5. The average atomic percent difference for any one element in a given phase was no more than $\sim 8.1$ at. $\%$ and as low as 2.0 at. $\%$. 


\subsection{Merit of Thermodynamic Predictions of Compositionally Complex Alloys}

To better evaluate the scientific merit of CALPHAD based models for predicting the phase equilibria of $\mathrm{AlNiCoCrFe} \mathrm{HEAs}$, isothermal phase fraction diagrams at $700^{\circ} \mathrm{C}$ and $1050^{\circ} \mathrm{C}$ were simulated, Fig. 9. Unlike the predictions used in Figs. 1(d), 3(d), 5(d), and 7(d), these calculated phase fractions illustrate the isothermal phase evolution over the expanded composition range of $\mathrm{Al}_{\mathrm{x}}(\mathrm{NiCoCrFe})_{100-\mathrm{x}}$ where $\mathrm{x}=5$ to 40 at. $\%$. As previously discussed, a combination of $\mathrm{FCC}, \mathrm{B} 2$, and/or BCC phases are predicted at $1050^{\circ} \mathrm{C}$ depending on the alloy composition, Fig. 9 (a). At low $\mathrm{Al}$ concentrations, $\sim 5$ at. \%, a single phase, solid solution FCC microstructure is predicted. This is beyond the composition range of the HEAs in this study, but is likely experimentally accurate when considering the results of this study, as well as the work of Wang et al. [11,56,61] on other AlNiCoCrFe HEAs. As the Al concentration is increased beyond $\sim 6-7$ at. $\%$, the solid solution phase is predicted to separate into FCC and B2 phases, with the phase fraction of B2 increasing at the expense of the FCC phase. This trend was observed in the $1050^{\circ} \mathrm{C}$ annealed $\mathrm{Al}_{10}$ and $\mathrm{Al}_{15} \mathrm{HEAs}$, Figs. 1(b) and 2(b). The experimental results at $1050^{\circ} \mathrm{C}$ appear to be very consistent with the modeling predictions up to the $\sim 15$ at. $\%$ level. As the $\mathrm{Al}$ concentration is increased further, two major observations can be made. The first is the stabilization of a BCC phase at $\sim 16$ at. $\% \mathrm{Al}$ and the full destabilization of the $\mathrm{FCC}$ phase at $\sim 20$ at. $\% \mathrm{Al}$. At exactly 20 at. \% $\mathrm{Al}$, a combination of $\mathrm{BCC}$ and $\mathrm{B} 2$ phases is predicted. However, as reported above, an additional FCC phase was found along the grain boundaries of the $1050^{\circ} \mathrm{C}$ annealed $\mathrm{Al}_{20} \mathrm{HEA}$, Figs. 5(b) and 6(f). This discrepancy is not too surprising since the $\mathrm{Al}_{20}$ HEA is the most compositionally complex and lies in the center of the AlNiCoCrFe phase diagram. As the $\mathrm{Al}$ concentration is increased further, up to 40 at. \%, a nearly constant ratio of $\mathrm{B} 2$ and $\mathrm{BCC}$ phases is predicted, which is fully consistent with the experimental results for the $\mathrm{Al}_{30} \mathrm{HEA}$ at $1050^{\circ} \mathrm{C}$. 
At $700^{\circ} \mathrm{C}$, a similar distribution of $\mathrm{FCC}, \mathrm{B} 2$, and/or $\mathrm{BCC}$ phases are predicted over the set composition range. However, an additional topologically close-packed (TCP) sigma phase is predicted over an extended range of alloys (5 to $\sim 28.5$ at. \% Al), Fig. 9 (b). This phase has been reported in a variety of relevant HEAs [70-7570-75] and is generally undesired due to its brittleness. At low $\mathrm{Al}$ concentrations ( 5 to 14.5 at. \%) a combination of FCC, B2, and sigma phases are predicted. Similar to the predicted behaviors at $1050^{\circ} \mathrm{C}$, increased $\mathrm{Al}$ content decreases the predicted phase fraction of FCC phase, while both the B2 and sigma phases tend to increase. The experimental observations of the $700^{\circ} \mathrm{C} \mathrm{Al} 10$ HEA correlate well with the simulated trends, Figs. 1(a) and 2(a). As the $\mathrm{Al}$ concentration is increased beyond 14.5 at. \%, the FCC phase is predicted to completely destabilize, leaving a mixture of $\mathrm{B} 2$ and sigma phases. Once the $\mathrm{Al}$ concentration reaches $\sim 22$ at. $\%$, a BCC phase is predicted to be stable. However, experimentally the $700^{\circ} \mathrm{C} \mathrm{Al} 1_{15} \mathrm{HEA}$ was found to contain $\mathrm{B} 2$, sigma, and $\mathrm{FCC}$ phases. The $700^{\circ} \mathrm{C} \mathrm{Al}_{20} \mathrm{HEA}$ exhibited B2, BCC, FCC, and sigma phases. The presence of the FCC phase in the $\mathrm{Al}_{15} \mathrm{HEA}$ and BCC phase in the $\mathrm{Al}_{20}$ HEA does not correlate with the simulations. This infers that the complete destabilization of the FCC phase likely occurs at a higher concentration of $\mathrm{Al}$, while the stabilization of the $\mathrm{BCC}$ phase occurs at a lower $\mathrm{Al}$ concentration. Once the $\mathrm{Al}$ concentration reaches $\sim 28.5$ at. $\%$, the sigma phase is predicted to be fully destabilized, leaving a combination of B2 and BCC phases. This apparent destabilization of the sigma phase is consistent with the experimental findings of the $700^{\circ} \mathrm{C} \mathrm{Al} 30 \mathrm{HEA}$, which contained only $\mathrm{B} 2$ and $\mathrm{BCC}$ phases.

The CALPHAD based thermodynamic models employed here were reasonably accurate in predicting the high temperature phase stabilities in a range of AlNiCoCrFe based HEAs. Also, the selected annealing times appeared to be sufficient for all of the HEAs to reach a metastable equilibrium state. In particular, the predicted stability range of sigma phase was consistent with 
all experimental observations. The only modeling discrepancies observed related to the composition where that the FCC phase is fully destabilized at $700^{\circ} \mathrm{C}$ and $1050^{\circ} \mathrm{C}$, as well as the composition where the BCC phase first becomes stable at $700^{\circ} \mathrm{C}$. No order/disorder inconsistencies were found in the high temperature range. Additionally, the predicted chemistries of each phase were also in agreement with those determined experimentally. Thus, it is suggested that the current thermodynamic databases, though reasonably correct, still require some improvement.

\section{Conclusions}

This work investigated the $700^{\circ} \mathrm{C}$ and $1050^{\circ} \mathrm{C}$ phase equilibria in $\mathrm{Al}_{10} \mathrm{Ni}_{22.5} \mathrm{Cr}_{22.5} \mathrm{Co}_{22.5} \mathrm{Fe}_{22.5}, \quad \mathrm{Al}_{15} \mathrm{Ni}_{21.25} \mathrm{Cr}_{21.25} \mathrm{Co}_{21.25} \mathrm{Fe}_{21.25}, \quad \mathrm{Al}_{20} \mathrm{Ni}_{20} \mathrm{Cr}_{20} \mathrm{Co}_{20} \mathrm{Fe}_{20}, \quad$ and $\mathrm{Al}_{30} \mathrm{Ni}_{17.5} \mathrm{Cr}_{17.5} \mathrm{Co}_{17.5} \mathrm{Fe}_{17.5}$ (at. \%) HEAs. Through the use of analytical characterization techniques, coupled with CALPHAD based thermodynamic modeling, the following can be concluded:

1) Annealing the $\mathrm{HEAs}$ at $1050^{\circ} \mathrm{C}$ promoted coarse microstructures consisting of $\mathrm{FCC}, \mathrm{BCC}$, and/or B2 phases depending on the relative Al content. Similarly, annealing at $700^{\circ} \mathrm{C}$ tended to stabilize a mixture of FCC, B2, BCC, and/or sigma phases. The B2 phases were commonly rich in $\mathrm{Ni}$ and $\mathrm{Al}$, while the $\mathrm{FCC}$ phases were $\mathrm{Co}, \mathrm{Cr}$, and $\mathrm{Fe}$ rich. When observed, the BCC phases exhibited higher $\mathrm{Cr}$ content than the $\mathrm{B} 2$ phases and the sigma phases were extensively rich in $\mathrm{Cr}$ and $\mathrm{Fe}$.

2) The experimentally determined phases were assessed using CALPHAD based thermodynamic modeling. In the majority of cases, the simulations predicted reasonably accurate phase fractions at temperatures of $700^{\circ} \mathrm{C}$ and $1050^{\circ} \mathrm{C}$ for a range of compositions. In general, the simulations also tended to capture experimentally observed trends in phase 
evolution with varied $\mathrm{Al}$ concentration. The predicted phase chemistries were also fairly consistent with those determined via TEM-EDS. The only discrepancies in the modeling were related to the compositions where the $\mathrm{FCC}$ phase destabilizes at $700^{\circ} \mathrm{C}$ and $1050^{\circ} \mathrm{C}$, along with when the $\mathrm{BCC}$ phase stabilizes at $700^{\circ} \mathrm{C}$. No other order/disorder or sigma phase discrepancies were observed.

3) The experimental and simulated results of this study demonstrate the usefulness of CALPHAD based models for predicting the phases that form in compositionally complex HEAs. The thermodynamic databases still need improvement, but have demonstrated their usefulness and merit in this study.

\section{Acknowledgement}

This work utilized equipment owned by the Central Analytical Facility (CAF), which is housed at the University of Alabama. The authors also acknowledge partial support from the National Science Foundation under grant DMR-1411280.

\section{References}

[1] R. C. Reed, The Superalloys, Fundamentals and Applications, (Cambridge University Press, Cambridge, 2006).

[2] J. W. Yeh, "Alloy design strategies and future trends in high-entropy alloys," JOM 65 (2013) 17591771.

[3] Y. Zhang, T. T. Zuo, Z. Tang, M. C. Gao, K. A. Dahmen, P. K. Liaw and Z. P. Lu, "Microstructures and properties of high-entropy alloys," Progress in Materials Science 61 (2014) 1-93.

[4] B. Cantor, I. T. H. Chang, P. Knight and A. J. B. Vincent, "Microstructural development in equiatomic multicomponent alloys," Materials Science and Engineering: A 375-377 (2004) 213218.

[5] Z. P. Lu, H. Wang, M. W. Chen, I. Baker, J. W. Yeh, C. T. Liu and T. G. Nieh, "An assessment on the future development of high-entropy alloys: Summary from a recent workshop," Intermetallics 66 (2015) 67-76.

[6] J. W. Yeh, "Recent progress in high-entropy alloys," Annales de Chimie: Science des Materiaux 31 (2006) 633-648.

[7] S. Guo, "Phase selection rules for cast high entropy alloys: An overview," Materials Science and Technology (United Kingdom) 31 (2015) 1223-1230. 
[8] X. Yang and Y. Zhang, "Prediction of high-entropy stabilized solid-solution in multi-component alloys," Materials Chemistry and Physics 132 (2012) 233-238.

[9] S. T. Chen, W.-Y. Tang, Y. F. Kuo, S. Y. Chen, C. H. Tsau, T. T. Shun and J. W. Yeh, "Microstructure and properties of age-hardenable $\mathrm{Al}_{\mathrm{x}} \mathrm{CrFe}_{1.5} \mathrm{MnNi}_{0.5}$ alloys," Materials Science and Engineering: A 527 (2010) 5818-5825.

[10] M. H. Chuang, M. H. Tsai, W. R. Wang, S. J. Lin and J. W. Yeh, "Microstructure and wear behavior of AlxCo1.5CrFeNi1.5Tiy high-entropy alloys," Acta Materialia 59 (2011) 6308-6317.

[11] W. R. Wang, W. L. Wang, S. C. Wang, Y. C. Tsai, C. H. Lai and J. W. Yeh, "Effects of Al addition on the microstructure and mechanical property of AlxCoCrFeNi high-entropy alloys," Intermetallics 26 (2012) 44-51.

[12] S. Praveen, B. S. Murty and R. S. Kottada, "Alloying behavior in multi-component AlCoCrCuFe and NiCoCrCuFe high entropy alloys," Materials Science and Engineering: A 534 (2012) 83-89.

[13] A. K. Singh and A. Subramaniam, "On the formation of disordered solid solutions in multicomponent alloys," Journal of Alloys and Compounds 587 (2014) 113-119.

[14] Y. J. Zhou, Y. Zhang, Y. L. Wang and G. L. Chen, "Solid solution alloys of AlCoCrFeNiTix with excellent room-temperature mechanical properties," Applied Physics Letters 90 (2007) -.

[15] Z. Tang, O. N. Senkov, C. M. Parish, C. Zhang, F. Zhang, L. J. Santodonato, G. Wang, G. Zhao, F. Yang and P. K. Liaw, "Tensile ductility of an AlCoCrFeNi multi-phase high-entropy alloy through hot isostatic pressing (HIP) and homogenization," Materials Science and Engineering: A 647 (2015) 229-240.

[16] J. M. Zhu, H. M. Fu, H. F. Zhang, A. M. Wang, H. Li and Z. Q. Hu, "Microstructure and compressive properties of multiprincipal component AlCoCrFeNiCx alloys," Journal of Alloys and Compounds 509 (2011) 3476-3480.

[17] P. K. Huang, J. W. Yeh, T. T. Shun and S. K. Chen, "Multi-Principal-Element Alloys with Improved Oxidation and Wear Resistance for Thermal Spray Coating," Advanced Engineering Materials 6 (2004) 74-78.

[18] C. M. Liu, H. M. Wang, S. Q. Zhang, H. B. Tang and A. L. Zhang, "Microstructure and oxidation behavior of new refractory high entropy alloys," Journal of Alloys and Compounds 583 (2014) 162169.

[19] H. Zhang, Q. T. Wang, Q. H. Tang and P. Q. Dai, "High temperature oxidation property of $\mathrm{Al}_{0.5} \mathrm{FeCoCrNi}\left(\mathrm{Si}_{0.2}, \mathrm{Ti}_{0.5}\right)$ high entropy alloys," Corrosion and Protection 34 (2013) 561-565.

[20] O. N. Senkov, S. V. Senkova, D. M. Dimiduk, C. Woodward and D. B. Miracle, "Oxidation behavior of a refractory $\mathrm{NbCrMo}_{0.5} \mathrm{Ta}_{0.5} \mathrm{TiZr}$ alloy," Journal of Materials Science 47 (2012) 65226534.

[21] C. Huang, Y. Zhang, J. Shen and R. Vilar, "Thermal stability and oxidation resistance of laser clad TiVCrAlSi high entropy alloy coatings on Ti-6Al-4V alloy," Surface and Coatings Technology 206 (2011) 1389-1395.

[22] H. Duan, Y. Wu, M. Hua, C. Yuan, D. Wang, J. Tu, H. Kou and J. Li, "Tribological properties of AlCoCrFeNiCu high-entropy alloys in hydrogen peroxide solution and in oil lubricant," Wear 297 (2013) 1045-1051.

[23] N. T. B. N. Koundinya, C. S. Babu, K. Sivaprasad, P. Susila, N. K. Babu and J. Baburao, "Phase evolution and thermal analysis of nanocrystalline AlCrCuFeNiZn high entropy alloy produced by mechanical alloying," Journal of Materials Engineering and Performance 22 (2013) 3077-3084.

[24] T. M. Butler, J. P. Alfano, R. L. Martens and M. L. Weaver, "High-Temperature Oxidation Behavior of Al-Co-Cr-Ni-(Fe or Si) Multicomponent High-Entropy Alloys," JOM 67 (2015) 246259.

[25] B. Gorr, M. Azim, H. J. Christ, T. Mueller, D. Schliephake and M. Heilmaier, "Phase equilibria, microstructure, and high temperature oxidation resistance of novel refractory high-entropy alloys," Journal of Alloys and Compounds 624 (2015) 270-278.

[26] J. Jiang and X. Luo, "High temperature oxidation behaviour of AlCuTiFeNiCr high-entropy alloy," Advanced Materials Research 652-654 (2013) 1115-1118. 
[27] H. M. Daoud, A. M. Manzoni, R. Volkl, N. Wanderka and U. Glatzel, "Oxidation behavior of $\mathrm{Al}_{8} \mathrm{Co}_{17} \mathrm{Cr}_{17} \mathrm{Cu}_{8} \mathrm{Fe}_{17} \mathrm{Ni}_{33}, \mathrm{Al}_{23} \mathrm{Co}_{15} \mathrm{Cr}_{23} \mathrm{Cu}_{8} \mathrm{Fe}_{15} \mathrm{Ni}_{15}$, and $\mathrm{Al}_{17} \mathrm{Co}_{17} \mathrm{Cr}_{17} \mathrm{Cu}_{17} \mathrm{Fe}_{17} \mathrm{Ni}_{17}$ compositionally complex alloys (high-entropy alloys) at elevated temperatures in air," Advanced Engineering Materials 17 (2015) 1134-1141.

[28] G. R. Holcomb, J. Tylczak and C. Carney, "Oxidation of CoCrFeMnNi High Entropy Alloys," JOM (2015).

[29] Y. X. Liu, C.-Q. Cheng, J. L. Shang, R. Wang, P. Li and J. Zhao, "Oxidation behavior of highentropy alloys AlxCoCrFeNi $(x=0.15,0.4)$ in supercritical water and comparison with HR3C steel," Transactions of Nonferrous Metals Society of China 25 (2015) 1341-1351.

[30] H. H. Yang, W. T. Tsai and J. C. Kuo, "Effect of pre-oxidation on increasing resistance of Fe-AlNi-Cr-Co-Mn high entropy alloys to molten Al attack," Corrosion Engineering Science and Technology 49 (2014) 124-129.

[31] S. Fang, X. Xiao, L. Xia, W. Li and Y. Dong, "Relationship between the widths of supercooled liquid regions and bond parameters of Mg-based bulk metallic glasses," Journal of Non-Crystalline Solids 321 (2003) 120-125.

[32] S. Guo and C. T. Liu, "Phase stability in high entropy alloys: Formation of solid-solution phase or amorphous phase," Progress in Natural Science: Materials International 21 (2011) 433-446.

[33] S. Guo, C. Ng, Z. Wang and C. T. Liu, "Solid solutioning in equiatomic alloys: Limit set by topological instability," Journal of Alloys and Compounds 583 (2014) 410-413.

[34] F. Otto, Y. Yang, H. Bei and E. P. George, "Relative effects of enthalpy and entropy on the phase stability of equiatomic high-entropy alloys," Acta Materialia 61 (2013) 2628-2638.

[35] J. W. Yeh, S. K. Chen, S. J. Lin, J. Y. Gan, T. S. Chin, T. T. Shun, C. H. Tsau and S. Y. Chang, "Nanostructured High-Entropy Alloys with Multiple Principal Elements: Novel Alloy Design Concepts and Outcomes," Advanced Engineering Materials 6 (2004) 299-303.

[36] F. Zhang, C. Zhang, S. L. Chen, J. Zhu, W. S. Cao and U. R. Kattner, "An understanding of high entropy alloys from phase diagram calculations," Calphad 45 (2014) 1-10.

[37] Y. Zhang and W. j. Peng, "Microstructural control and properties optimization of high-entrop alloys," Procedia Engineering 27 (2012) 1169-1178.

[38] Y. Zhang, T. T. Zuo, Z. Tang, M. C. Gao, K. A. Dahmen, P. K. Liaw and Z. P. Lu, "Microstructures and properties of high-entropy alloys," Progress in Materials Science 61 (2014) 1-93.

[39] Y. Zhang, X. Yang and P. K. Liaw, "Alloy Design and Properties Optimization of High-Entropy Alloys," JOM 64 (2012) 830-838.

[40] Y. Zhang, Y. J. Zhou, J. P. Lin, G. L. Chen and P. K. Liaw, "Solid-Solution Phase Formation Rules for Multi-component Alloys," Advanced Engineering Materials 10 (2008) 534-538.

[41] W. P. Huhn and M. Widom, "Prediction of A2 to B2 phase transition in the high-entropy alloy MoNb-Ta-W," JOM 65 (2013) 1772-1779.

[42] M. Widom, W. P. Huhn, S. Maiti and W. Steurer, "Hybrid Monte Carlo/molecular dynamics simulation of a refractory metal high entropy alloy," Metallurgical and Materials Transactions A: Physical Metallurgy and Materials Science 45 (2014) 196-200.

[43] A. Sharma, P. Singh, P. Liaw and D. D. Johnson, "Atomistic clustering-ordering and high-strain deformation of an Al0.1CrCoFeNi high-entropy alloy," Scientific Reports (2016).

[44] P. Singh, A. V. Smirnov and D. D. Johnson, "Atomic short-range and incipient long-range order in high-entropy alloys," Physical Review B 91 (2015) 224204.

[45] D. Ma, B. Grabowski, F. Kormann, J. Neugebauer and D. Raabe, "Ab initio thermodynamics of the CoCrFeMnNi high entropy alloy: Importance of entropy contributions beyond the configurational one," Acta Materialia 100 (2015) 90-97.

[46] F. Tian, L. Delczeg, N. Chen, L. K. Varga, J. Shen and L. Vitos, "Structural stability of NiCoFeCrAlx high-entropy alloy from ab initio therory," Phys. Rev. B 88 (2013) 085128.

[47] F. Tian, L. K. Varga, N. Chen, L. Delczeg and L. Vitos, "Ab initio investigation of high-entropy alloys of 3d elements," Phys. Rev. B 87 (2013) 075144. 
[48] A. Manzoni, H. Daoud, S. Mondal, S. van Smaalen, R. Völkl, U. Glatzel and N. Wanderka, "Investigation of phases in A123Co15Cr23Cu8Fe15Ni16 and Al8Co17Cr17Cu8Fe17Ni33 high entropy alloys and comparison with equilibrium phases predicted by Thermo-Calc," Journal of Alloys and Compounds 552 (2013) 430-436.

[49] C. Ng, S. Guo, J. Luan, S. Shi and C. T. Liu, "Entropy-driven phase stability and slow diffusion kinetics in an Al0.5CoCrCuFeNi high entropy alloy," Intermetallics 31 (2012) 165-172.

[50] C. Zhang, F. Zhang, S. Chen and W. Cao, "Computational Thermodynamics Aided High-Entropy Alloy Design," JOM 64 (2012) 839-845.

[51] U. Kattner, "The thermodynamic modeling of multicomponent phase equilibria," JOM 49 (1997) 14-19.

[52] D. Ma, M. Yao, K. G. Pradeep, C. C. Tasan, H. Springer and D. Raabe, "Phase stability of nonequiatomic CoCrFeMnNi high entropy alloys," Acta Materialia 98 (2015) 288-296.

[53] C. Ng, S. Guo, J. Luan, Q. Wang, J. Lu, S. Shi and C. T. Liu, "Phase stability and tensile properties of Co-free Al0.5CrCuFeNi2 high-entropy alloys," Journal of Alloys and Compounds 584 (2014) 530-537.

[54] ThermoCalc 2015a, (ThermoCalc Software AB, Stckholm, Sweden, 2015)

[55] Q. H. Tang, Y. Huang, Y. Y. Huang, X. Z. Liao, T. G. Langdon and P. Q. Dai, "Hardening of an Al0.3CoCrFeNi high entropy alloy via high-pressure torsion and thermal annealing," Materials Letters 151 (2015) 126-129.

[56] W. R. Wang, W. L. Wang and J. W. Yeh, "Phases, microstructure and mechanical properties of AlxCoCrFeNi high-entropy alloys at elevated temperatures," Journal of Alloys and Compounds 589 (2014) 143-152.

[57] D. B. Miracle, J. D. Miller, O. N. Senkov, C. Woodward, M. D. Uchic and J. Tiley, "Exploration and Development of High Entropy Alloys for Structural Applications," Entropy 16 (2014) 494525 .

[58] A. Manzoni, H. Daoud, R. Völkl, U. Glatzel and N. Wanderka, "Phase separation in equiatomic AlCoCrFeNi high-entropy alloy," Ultramicroscopy 132 (2013) 212-215.

[59] J. C. Huang, "Evaluation of tribological behavior of Al-Co-Cr-Fe-Ni high entropy alloys using molecular dynamics simulation," Scanning 34 (2012) 325-331.

[60] Y. F. Kao, T. J. Chen, S. K. Chen and J. W. Yeh, "Microstructure and mechanical property of ascast, -homogenized, and -deformed AlxCoCrFeNi $(0 \leq \mathrm{x} \leq 2)$ high-entropy alloys," Journal of Alloys and Compounds 488 (2009) 57-64.

[61] Y. P. Wang, B. S. Li, M. X. Ren, C. Yang and H. Z. Fu, "Microstructure and compressive properties of AlCrFeCoNi high entropy alloy," Materials Science and Engineering: A 491 (2008) 154-158.

[62] ThermoCalc Ni-based Superalloys Database, TCNI8, (ThermoCalc Software AB, Stockholm, Sweden, 2015)

[63] D. Tomus and H. P. Ng, "In situ lift-out dedicated techniques using FIB-SEM system for TEM specimen preparation," Micron 44 (2013) 115-119.

[64] FEI-Company, ES Vision, 2004) 4.1.193.

[65] ThermoCalc High Entropy Alloy Database, TCHEA1, (ThermoCalc Software AB, Stockholm, Sweden, 2015)

[66] ThermoCalc Steels/Fe-Alloys Database, TCFE8, (ThermoCalc Software AB, Stockhold, Sweden, 2015)

[67] F. Zhang and U. Kattner, "CALPHAD and the High Entropy Alloy," Journal of Phase Equilibria and Diffusion 36 (2015) 1-2.

[68] T. M. Butler and M. L. Weaver, "Investigation of the Microstructures and Oxidation Behavior of AlNiCoCrFe High-Entropy Alloys," in Contributed Papers from Materials Science \& Technology (MS\&T) 2015 (TMS, Columbus, OH, 2015) p. 1257-1264.

[69] T. M. Butler and M. L. Weaver, "Oxidation behavior of arc melted AlCoCrFeNi multi-component high entropy alloys," Journal of Alloys and Compounds 674 (2016) 229-244. 
[70] C. Y. Hsu, W. R. Wang, W. Y. Tang, S. K. Chen and J. W. Yeh, "Microstructure and mechanical properties of new AlCoxCrFeMo 0.5Ni high-entropy alloys," Advanced Engineering Materials 12 (2010) 44-49.

[71] C. Y. Hsu, C. C. Juan, W. R. Wang, T. S. Sheu, J. W. Yeh and S. K. Chen, "On the superior hot hardness and softening resistance of AlCoCrxFeMo0.5Ni high-entropy alloys," Materials Science and Engineering: A 528 (2011) 3581-3588.

[72] C. C. Juan, C. Y. Hsu, C. W. Tsai, W. R. Wang, T. S. Sheu, J. W. Yeh and S. K. Chen, "On microstructure and mechanical performance of $\mathrm{AlCoCrFeMo}{ }_{0.5} \mathrm{Ni}_{\mathrm{x}}$ high-entropy alloys," Intermetallics 32 (2013) 401-407.

[73] T. T. Shun, L. Y. Chang and M. H. Shiu, "Microstructures and mechanical properties of multiprincipal component CoCrFeNiTix alloys," Materials Science and Engineering: A 556 (2012) 170-174.

[74] T. T. Shun, C. H. Hung and C. F. Lee, "The effects of secondary elemental Mo or Ti addition in $\mathrm{Al} 0.3 \mathrm{CoCrFeNi}$ high-entropy alloy on age hardening at $700{ }^{\circ} \mathrm{C}, "$ Journal of Alloys and Compounds 495 (2010) 55-58.

[75] M. H. Tsai, H. Yuan, G. Cheng, W. Xu, W. W. Jian, M. H. Chuang, C. C. Juan, A. C. Yeh, S. J. Lin and Y. Zhu, "Significant hardening due to the formation of a sigma phase matrix in a high entropy alloy," Intermetallics 33 (2013) 81-86. 
Table 1. The overall chemical compositions of the as-cast HEAs in this study (at. \%).

\begin{tabular}{lllllll}
\hline Alloy & & Al & Ni & Co & Cr & Fe \\
\hline $\mathbf{A l}_{\mathbf{1 0}}$ & Target & 10 & 22.5 & 22.5 & 22.5 & 22.5 \\
& EDS & $10.2 \pm 0.2$ & $23.6 \pm 0.2$ & $21.7 \pm 0.1$ & $22.6 \pm 0.2$ & $21.8 \pm 0.2$ \\
\hline $\mathbf{A l}_{\mathbf{1 5}}$ & Target & 15 & 21.25 & 21.25 & 21.25 & 21.25 \\
& EDS & $15.6 \pm 0.1$ & $20.5 \pm 0.1$ & $20.8 \pm 0.1$ & $21.9 \pm 0.1$ & $21.1 \pm 0.1$ \\
\hline $\mathbf{A l}_{\mathbf{2 0}}$ & Target & 20 & 20 & 20 & 20 & 20 \\
& EDS & $20.2 \pm 0.1$ & $19.3 \pm 0.1$ & $19.7 \pm 0.1$ & $20.8 \pm 0.2$ & $20.1 \pm 0.1$ \\
\hline $\mathbf{A l}_{\mathbf{3 0}}$ & Target & 30 & 17.5 & 17.5 & 17.5 & 17.5 \\
& EDS & $29.2 \pm 0.2$ & $17.4 \pm 0.1$ & $17.6 \pm 0.1$ & $18.3 \pm 0.1$ & $17.6 \pm 0.1$ \\
\hline
\end{tabular}


Table 2. Phase compositions of the annealed $\mathrm{Al}_{10} \mathrm{Ni}_{22.5} \mathrm{Cr}_{22.5} \mathrm{Co}_{22.5} \mathrm{Fe}_{22.5} \mathrm{HEA}$ determined via TEM-EDS (at.\%). The thermodynamically predicted phase chemistries at $700^{\circ} \mathrm{C}$ and $1050^{\circ} \mathrm{C}$ are also shown for comparison. The average difference (at. \%) between the experimental and predicted values for all of the elements in a given phase are also shown.

\begin{tabular}{|c|c|c|c|c|c|c|c|}
\hline Temp. & Phase & Al & $\mathbf{N i}$ & Co & $\mathrm{Cr}$ & $\mathbf{F e}$ & Average Difference (at. $\%$ ) \\
\hline \multirow[t]{6}{*}{$700^{\circ} \mathrm{C}$} & $\mathrm{FCC}$ & $2.9 \pm 1.5$ & $23.6 \pm 4.8$ & $24.0 \pm 2.4$ & $25.7 \pm 1.1$ & $23.8 \pm 2.3$ & 1.9 \\
\hline & FCC (Predicted) & 1.6 & 26.2 & 21.8 & 24.3 & 26.2 & -- \\
\hline & B2 & $22.4 \pm 1.1$ & $48.7 \pm 0.7$ & $14.9 \pm 0.2$ & $3.0 \pm 0.5$ & $11.0 \pm 0.1$ & 8.3 \\
\hline & B2 (Predicted) & 21.7 & 28.7 & 22.4 & 7.3 & 19.9 & -- \\
\hline & Sigma & $1.1 \pm 1.2$ & $4.1 \pm 2.1$ & $21.4 \pm 0.9$ & $54.5 \pm 1.8$ & $19.0 \pm 0.5$ & 1.3 \\
\hline & Sigma (Predicted) & 0 & 7.2 & 20.0 & 54.7 & 18.2 & -- \\
\hline \multirow[t]{4}{*}{$1050^{\circ} \mathrm{C}$} & FCC & $4.5 \pm 0.4$ & $22.2 \pm 0.7$ & $25.0 \pm 0.6$ & $24.7 \pm 0.9$ & $23.5 \pm 1.0$ & 1.3 \\
\hline & FCC (Predicted) & 5.5 & 21.7 & 22.3 & 26.8 & 23.8 & -- \\
\hline & B2 & $23.3 \pm 0.8$ & $42.0 \pm 0.5$ & $17.7 \pm 0.7$ & $5.3 \pm 0.7$ & $11.7 \pm 0.4$ & 4.8 \\
\hline & B2 (Predicted) & 26.2 & 30.0 & 19.8 & 8.8 & 15.2 & -- \\
\hline
\end{tabular}


Table 3. Phase compositions of the annealed $\mathrm{Al}_{15} \mathrm{Ni}_{21.25} \mathrm{Cr}_{21.25} \mathrm{Co}_{21.25} \mathrm{Fe}_{21.25}$ HEA determined via TEM-EDS (at.\%). The thermodynamically predicted phase chemistries at $700^{\circ} \mathrm{C}$ and $1050^{\circ} \mathrm{C}$ are also shown for comparison. The average difference (at. \%) between the experimental and predicted values for all of the elements in a given phase are also shown.

\begin{tabular}{lllllllc}
\hline Temp. & Phase & Al & Ni & Co & Cr & Fe & Average Difference (at. \%) \\
\hline $\mathbf{7 0 0}^{\circ} \mathbf{C}$ & B2 & $22.1 \pm 0.5$ & $37.6 \pm 0.4$ & $18.8 \pm 1.3$ & $7.5 \pm 1.7$ & $13.9 \pm 1.2$ & 4.5 \\
& B2 (Predicted) & 23.2 & 27.6 & 22.4 & 6.2 & 20.5 & -- \\
& FCC & $4.2 \pm 0.2$ & $17.6 \pm 0.5$ & $25.2 \pm 1.7$ & $29.2 \pm 0.9$ & $23.8 \pm 0.7$ & N/A \\
& FCC (Predicted) & -- & -- & -- & -- & -- & -- \\
& Sigma & $0.6 \pm 0.2$ & $5.0 \pm 1.1$ & $20.1 \pm 2.2$ & $53.1 \pm 1.6$ & $21.4 \pm 0.6$ & 1.3 \\
& Sigma (Predicted) & 0 & 5.6 & 17.4 & 54.7 & 22.3 & -- \\
\hline $\mathbf{1 0 5 0}^{\circ} \mathbf{C}$ & FCC & $3.5 \pm 0.2$ & $19.5 \pm 0.4$ & $24.9 \pm 0.3$ & $26.9 \pm 0.4$ & $25.2 \pm 0.2$ & 2.6 \\
& FCC (Predicted) & 5.0 & 16.2 & 21.7 & 31.2 & 25.9 & -- \\
& B2 & $21.1 \pm 0.5$ & $38.5 \pm 4.3$ & $19.0 \pm 0.6$ & $8.7 \pm 4.5$ & $12.6 \pm 0.6$ & 4.7 \\
& B2 (Predicted) & 26.2 & 26.9 & 20.7 & 10.1 & 16.1 & -- \\
\hline
\end{tabular}


Table 4. Phase compositions of the annealed $\mathrm{Al}_{20} \mathrm{Ni}_{20} \mathrm{Cr}_{20} \mathrm{Co}_{20} \mathrm{Fe}_{20} \mathrm{HEA}$ determined via TEM-EDS (at.\%). The thermodynamically predicted phase chemistries at $700^{\circ} \mathrm{C}$ and $1050^{\circ} \mathrm{C}$ are also shown for comparison. The average difference (at. \%) between the experimental and predicted values for all of the elements in a given phase are also shown.

\begin{tabular}{|c|c|c|c|c|c|c|c|}
\hline Temp. & Phase & Al & $\mathbf{N i}$ & Co & $\mathrm{Cr}$ & $\mathbf{F e}$ & Average Difference (at. \%) \\
\hline \multirow[t]{8}{*}{$700^{\circ} \mathrm{C}$} & $\mathrm{B} 2$ & $22.7 \pm 3.5$ & $36.0 \pm 1.3$ & $23.6 \pm 1.0$ & $2.9 \pm 0.5$ & $14.7 \pm 1.3$ & 4.2 \\
\hline & B2 (Predicted) & 29.1 & 26.7 & 22.6 & 4.7 & 17.0 & -- \\
\hline & $\mathrm{FCC}$ & $1.2 \pm 0.4$ & $7.7 \pm 3.2$ & $22.3 \pm 1.6$ & $44.0 \pm 5.9$ & $24.9 \pm 1.8$ & $\mathrm{~N} / \mathrm{A}$ \\
\hline & FCC (Predicted) & -- & -- & -- & -- & -- & -- \\
\hline & $\mathrm{BCC}$ & $8.5 \pm 1.7$ & $15.8 \pm 3.4$ & $19.2 \pm 2.3$ & $33.6 \pm 5.4$ & $22.9 \pm 1.0$ & $\mathrm{~N} / \mathrm{A}$ \\
\hline & BCC (Predicted) & -- & -- & -- & -- & -- & -- \\
\hline & Sigma & $1.7 \pm 0.8$ & $3.4 \pm 0.6$ & $10.2 \pm 3.5$ & $51.4 \pm 2.3$ & $33.3 \pm 1.6$ & 3.5 \\
\hline & Sigma (Predicted) & 0 & 2.7 & 13.3 & 56.9 & 27.0 & -- \\
\hline \multirow[t]{6}{*}{$\mathbf{1 0 5 0}^{\circ} \mathrm{C}$} & $\mathrm{B} 2$ & $18.7 \pm 1.8$ & $32.9 \pm 2.1$ & $22.6 \pm 1.4$ & $10.2 \pm 2.6$ & $15.6 \pm 0.9$ & 3.6 \\
\hline & B2 (Predicted) & 25.7 & 24.9 & 21.5 & 10.2 & 17.7 & -- \\
\hline & FCC & $4.2 \pm 0.3$ & $14.0 \pm 0.8$ & $24.8 \pm 0.6$ & $28.5 \pm 0.6$ & $28.4 \pm 0.8$ & $\mathrm{~N} / \mathrm{A}$ \\
\hline & FCC (Predicted) & -- & -- & -- & -- & -- & -- \\
\hline & $\mathrm{BCC}$ & $1.3 \pm 0.5$ & $4.1 \pm 1.0$ & $19.4 \pm 0.8$ & $47.2 \pm 1.9$ & $28.0 \pm 0.3$ & 5.2 \\
\hline & BCC (Predicted) & 7.7 & 9.1 & 15.7 & 38.0 & 29.5 & -- \\
\hline
\end{tabular}


Table 5. Phase compositions of the annealed $\mathrm{Al}_{30} \mathrm{Ni}_{17.5} \mathrm{Cr}_{17.5} \mathrm{Co}_{17.5} \mathrm{Fe}_{17.5} \mathrm{HEA}$ determined via TEM-EDS (at.\%). The thermodynamically predicted phase chemistries at $700^{\circ} \mathrm{C}$ and $1050^{\circ} \mathrm{C}$ are also shown for comparison. The average difference (at. \%) between the experimental and predicted values for all of the elements in a given phase are also shown.

\begin{tabular}{|c|c|c|c|c|c|c|c|}
\hline Temp. & Phase & Al & $\mathrm{Ni}$ & Co & $\mathrm{Cr}$ & $\mathrm{Fe}$ & Average Difference (at. \%) \\
\hline \multirow[t]{4}{*}{$700^{\circ} \mathrm{C}$} & $\mathrm{B} 2$ & $35.3 \pm 3.0$ & $26.5 \pm 0.9$ & $24.9 \pm 1.5$ & $1.8 \pm 0.1$ & $11.6 \pm 1.3$ & 2.0 \\
\hline & B2 (Predicted) & 38.0 & 23.3 & 23.1 & 1.9 & 13.7 & -- \\
\hline & $\mathrm{BCC}$ & $7.8 \pm 0.2$ & $6.5 \pm 0.3$ & $10.1 \pm 0.1$ & $46.5 \pm 0.3$ & $29.1 \pm 0.1$ & 8.1 \\
\hline & BCC (Predicted) & 2.7 & 0.1 & 1.3 & 66.8 & 29.1 & -- \\
\hline \multirow[t]{4}{*}{$1050^{\circ} \mathrm{C}$} & $\mathrm{B} 2$ & $27.4 \pm 1.6$ & $28.8 \pm 1.9$ & $23.8 \pm 1.5$ & $5.9 \pm 1.7$ & $14.0 \pm 0.4$ & 4.1 \\
\hline & B2 (Predicted) & 35.9 & 21.9 & 20.1 & 6.4 & 15.1 & -- \\
\hline & $\mathrm{BCC}$ & $1.9 \pm 0.3$ & $1.2 \pm 0.7$ & $13.1 \pm 1.4$ & $52.4 \pm 1.7$ & $31.3 \pm 0.7$ & 4.7 \\
\hline & BCC (Predicted) & 9.6 & 5.4 & 10.2 & 48.5 & 26.3 & -- \\
\hline
\end{tabular}


Todd M. Butler, JALCOM 38623,

Investigation of the Phase Stabilities in AINiCoCrFe High Entropy Alloys

Figure 1. BSE images with inset higher magnification images of the $\mathrm{Al}_{10} \mathrm{HEA}$ after heat treating at $700^{\circ} \mathrm{C}$ for 1000 hours (a) and $1050^{\circ} \mathrm{C}$ for 520 hours (b); XRD spectra captured from the heat treated $\mathrm{Al}_{10} \mathrm{HEA}(\mathrm{c})$; and calculated phase fractions as a function of temperature for the $\mathrm{Al}_{10}$ HEA using the TCNI8 database in ThermoCalc (d).

Figure 2. STEM-HAADF images of the $\mathrm{Al}_{10} \mathrm{HEA}$ annealed at $700^{\circ} \mathrm{C}$ (a) and $1050^{\circ} \mathrm{C}$ (f), along with corresponding SADPs (b)-(e) and (g)-(i), respectively.

Figure 3. BSE images with inset higher magnification images of the $\mathrm{Al}_{15} \mathrm{HEA}$ after heat treating at $700^{\circ} \mathrm{C}$ for 1000 hours (a) and $1050^{\circ} \mathrm{C}$ for 520 hours (b); XRD spectra captured from the heat treated $\mathrm{Al}_{15} \mathrm{HEA}(\mathrm{c})$; and calculated phase fractions as a function of temperature for the $\mathrm{Al}_{15}$ HEA using the TCNI8 database in ThermoCalc (d).

Figure 4. STEM-HAADF images of the $\mathrm{Al}_{15} \mathrm{HEA}$ annealed at $700^{\circ} \mathrm{C}$ (a) and $1050^{\circ} \mathrm{C}(\mathrm{e})$, along with corresponding SADPs (b)-(d) and (f)-(h), respectively.

Figure 5. BSE images with inset higher magnification images of the $\mathrm{Al}_{20} \mathrm{HEA}$ after heat treating at $700^{\circ} \mathrm{C}$ for 1000 hours (a) and $1050^{\circ} \mathrm{C}$ for 520 hours (b); XRD spectra captured from the heat treated $\mathrm{Al}_{20} \mathrm{HEA}(\mathrm{c})$; and calculated phase fractions as a function of temperature for the $\mathrm{Al}_{20}$ HEA using the TCNI8 database in ThermoCalc (d).

Figure 6. STEM-HAADF images of the $\mathrm{Al}_{20} \mathrm{HEA}$ annealed at $700^{\circ} \mathrm{C}$ (a) and $1050^{\circ} \mathrm{C}$ (f), along with corresponding SADPs (b)-(e) and (g)-(i), respectively.

Figure 7. BSE images with inset higher magnification images of the $\mathrm{Al}_{30} \mathrm{HEA}$ after heat treating at $700^{\circ} \mathrm{C}$ for 1000 hours (a) and $1050^{\circ} \mathrm{C}$ for 520 hours (b); XRD spectra captured from the heat treated $\mathrm{Al}_{30} \mathrm{HEA}$ (c); and calculated phase fractions for the $\mathrm{Al}_{30} \mathrm{HEA}$ using the TCNI8 database in ThermoCalc (d).

Figure 8. STEM-HAADF images of the $\mathrm{Al}_{30} \mathrm{HEA}$ annealed at $700^{\circ} \mathrm{C}$ (a) and $1050^{\circ} \mathrm{C}(\mathrm{e})$, along with corresponding SADPs (b)-(d) and (f)-(i), respectively.

Figure 9. Calculated phase fractions as a function of composition at $1050^{\circ} \mathrm{C}$ (a) and $700^{\circ} \mathrm{C}$ (b) for $\mathrm{Al}_{\mathrm{x}}(\mathrm{NiCoCrFe})_{100-\mathrm{x}}$ alloys where $\mathrm{x}=5$ to 40 (at. \%). Simulations were conducted with the TCNI8 database in ThermoCalc. 

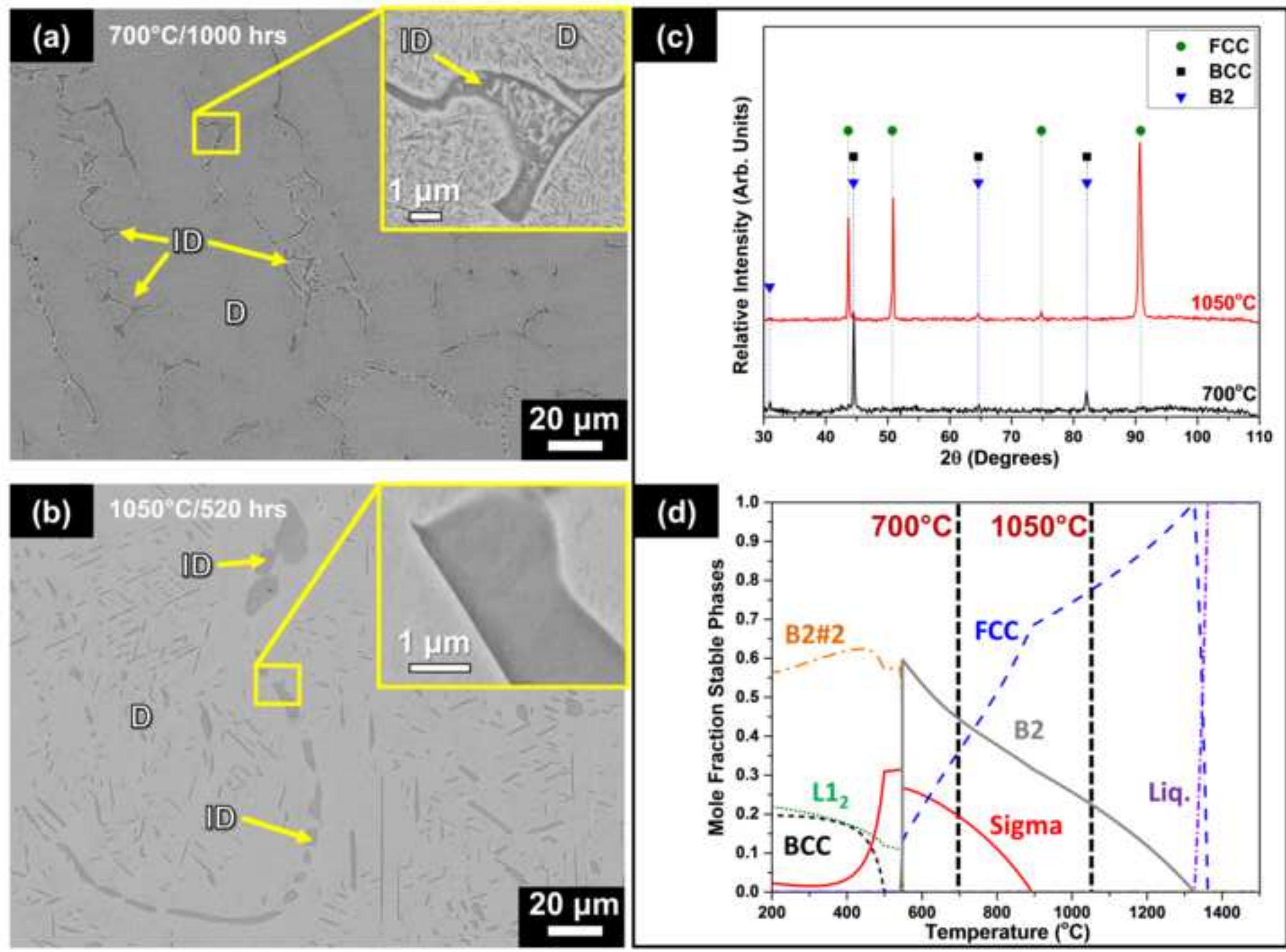


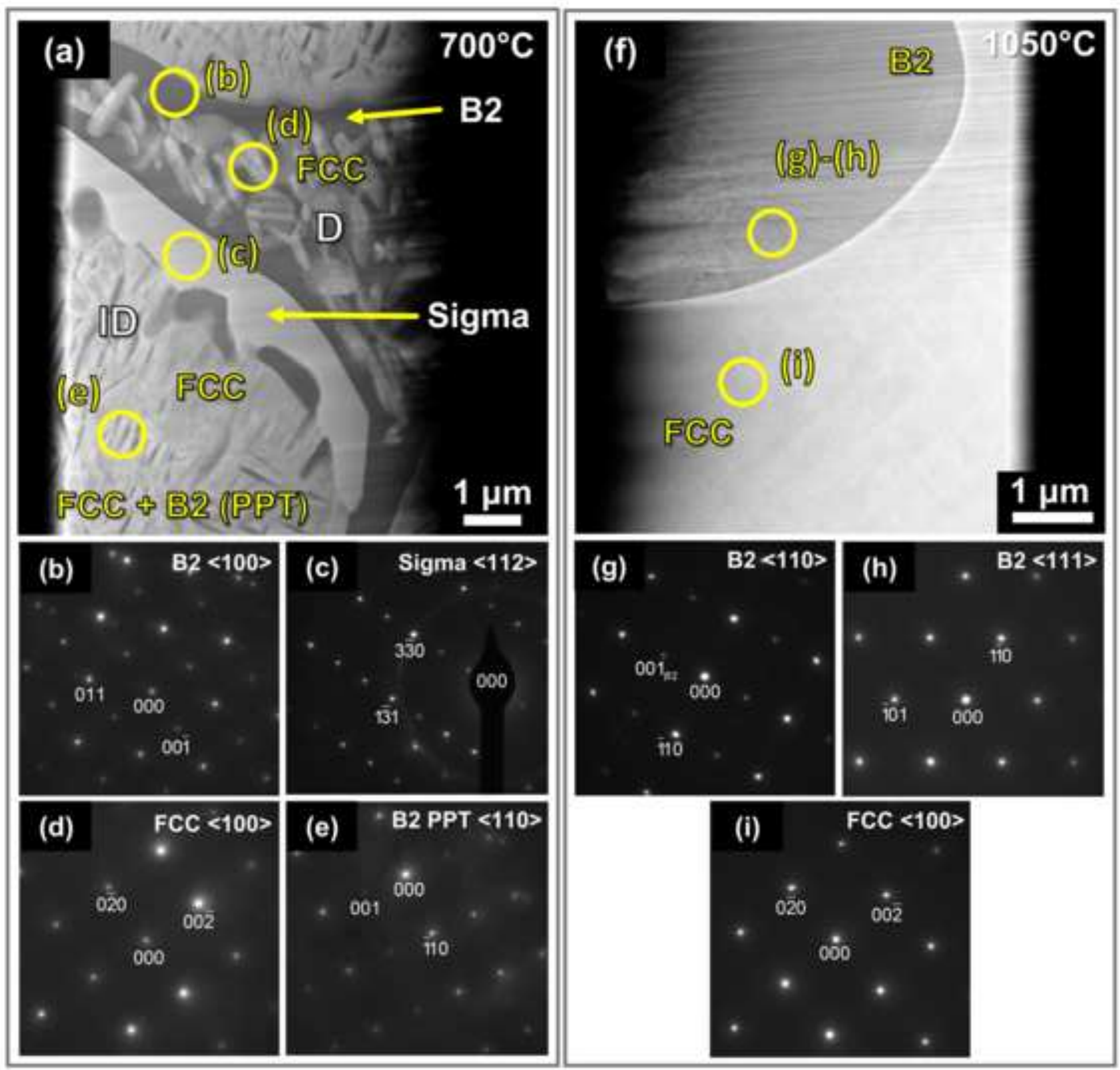



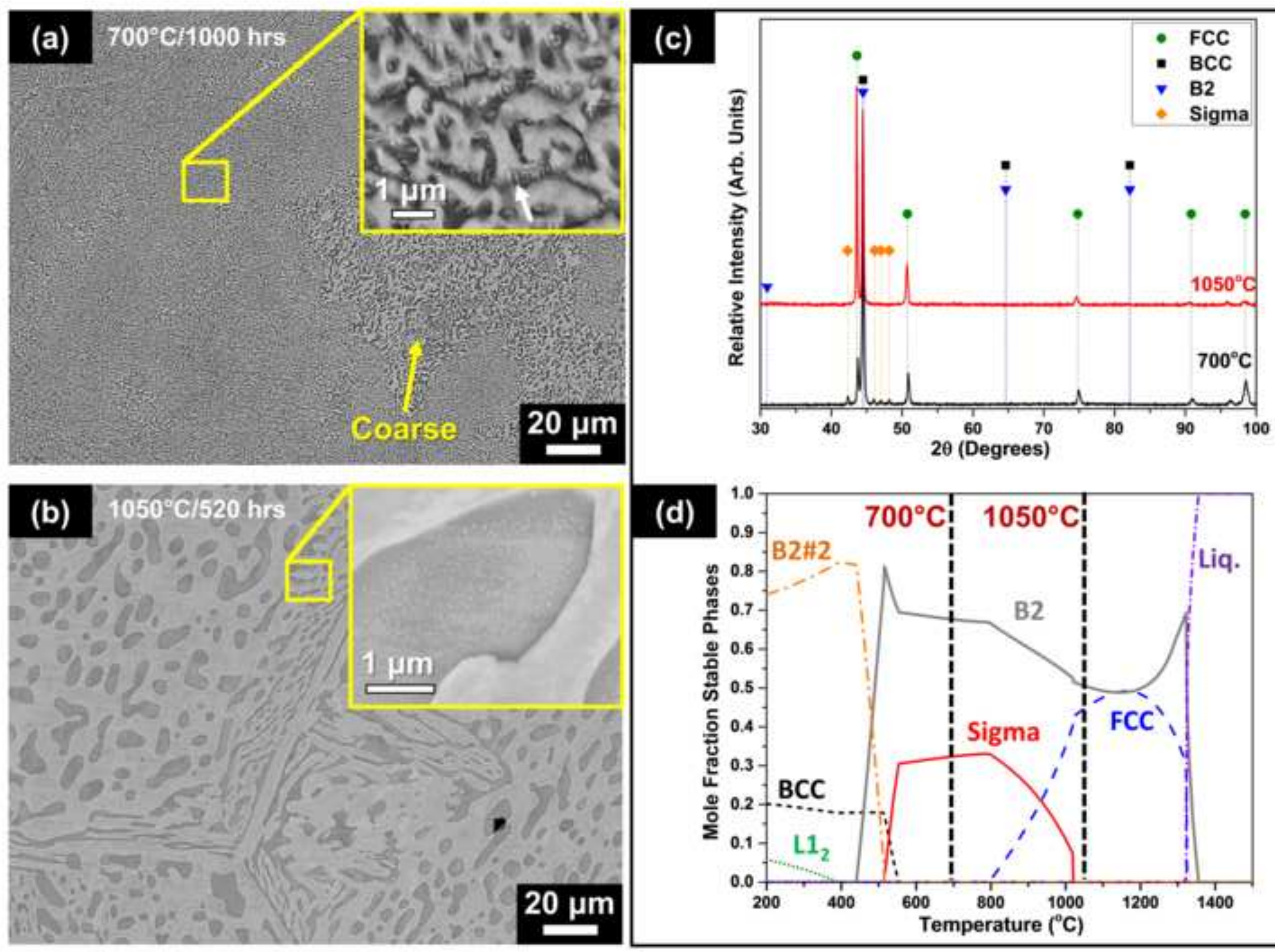


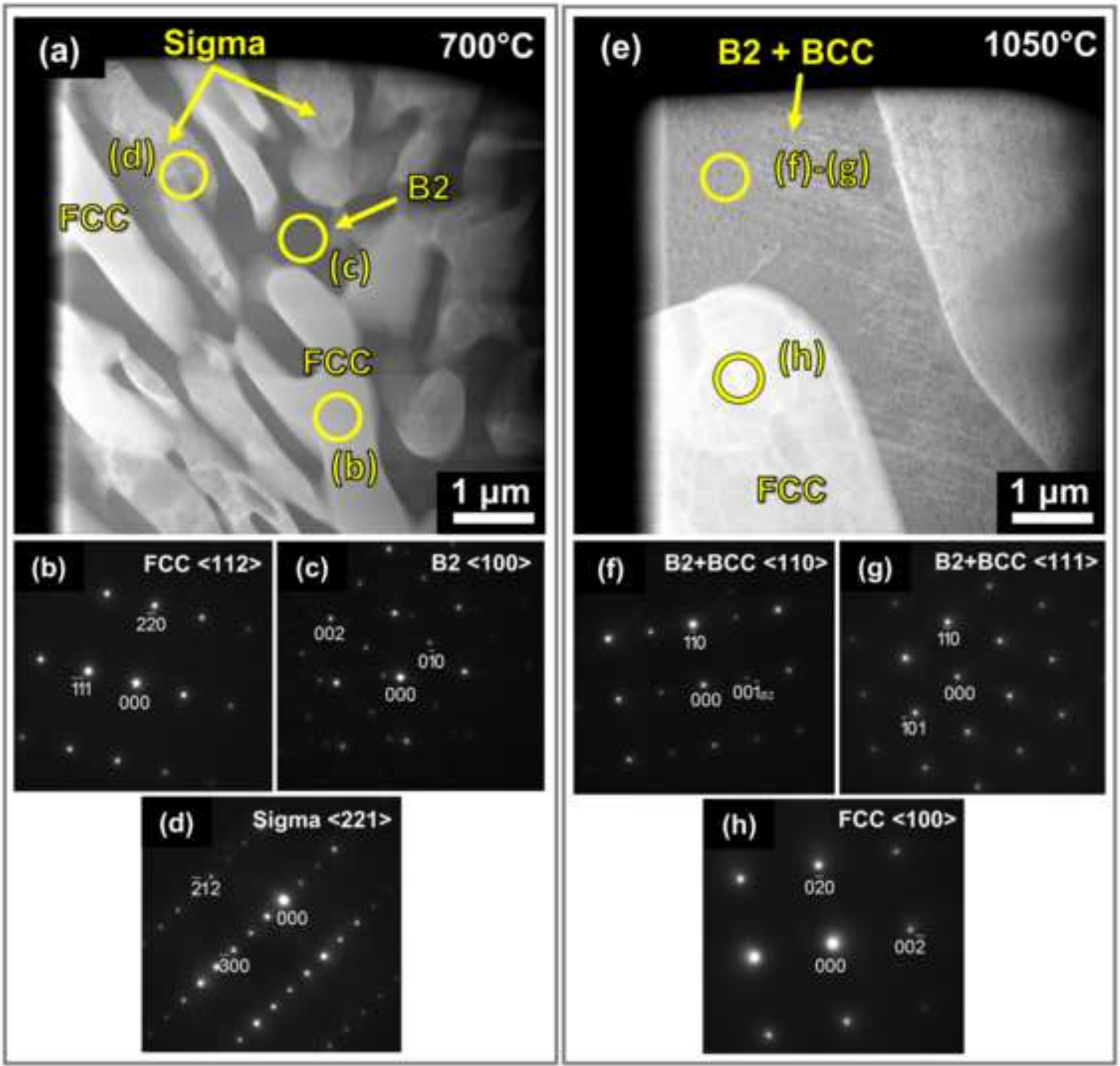



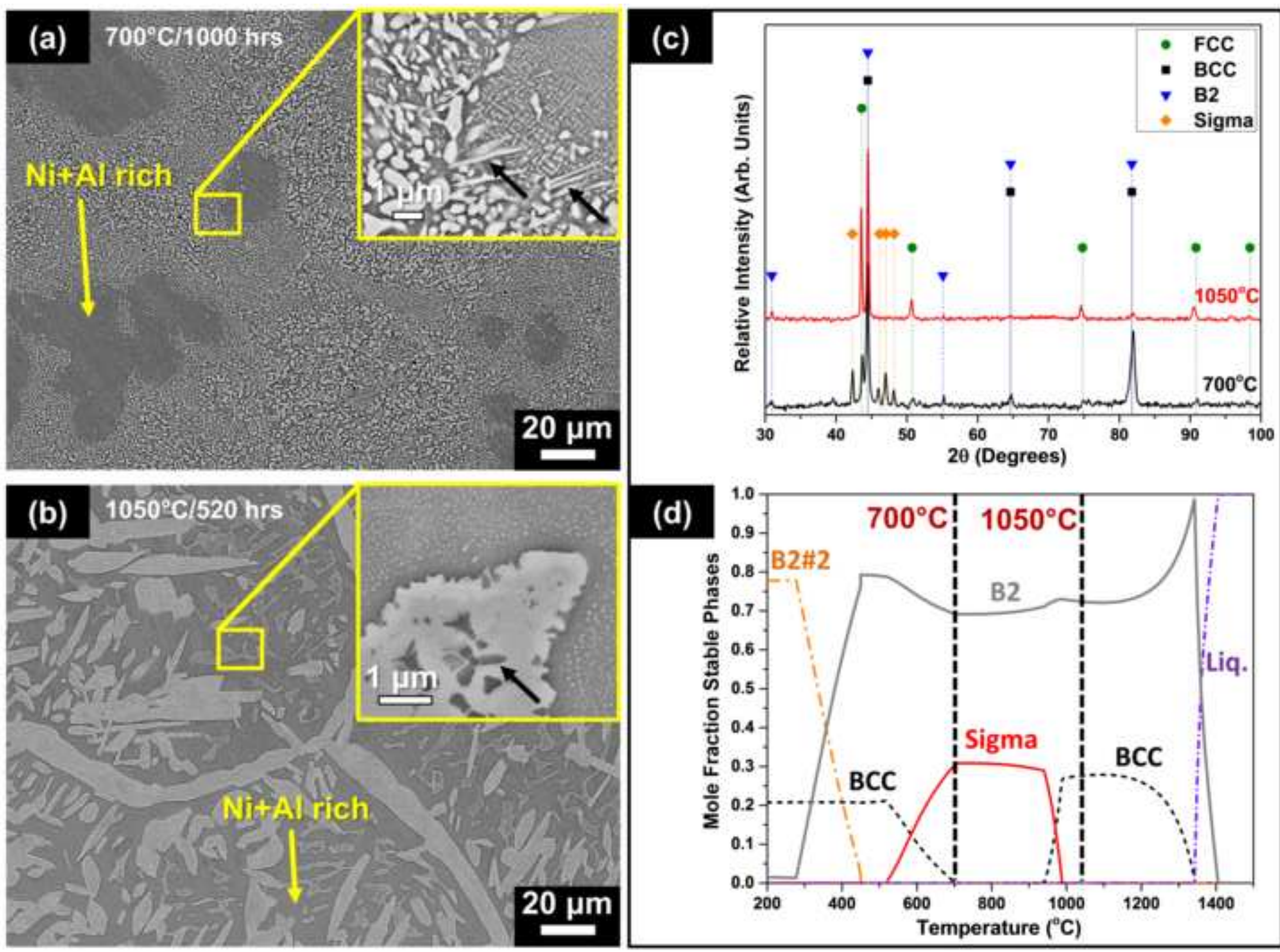


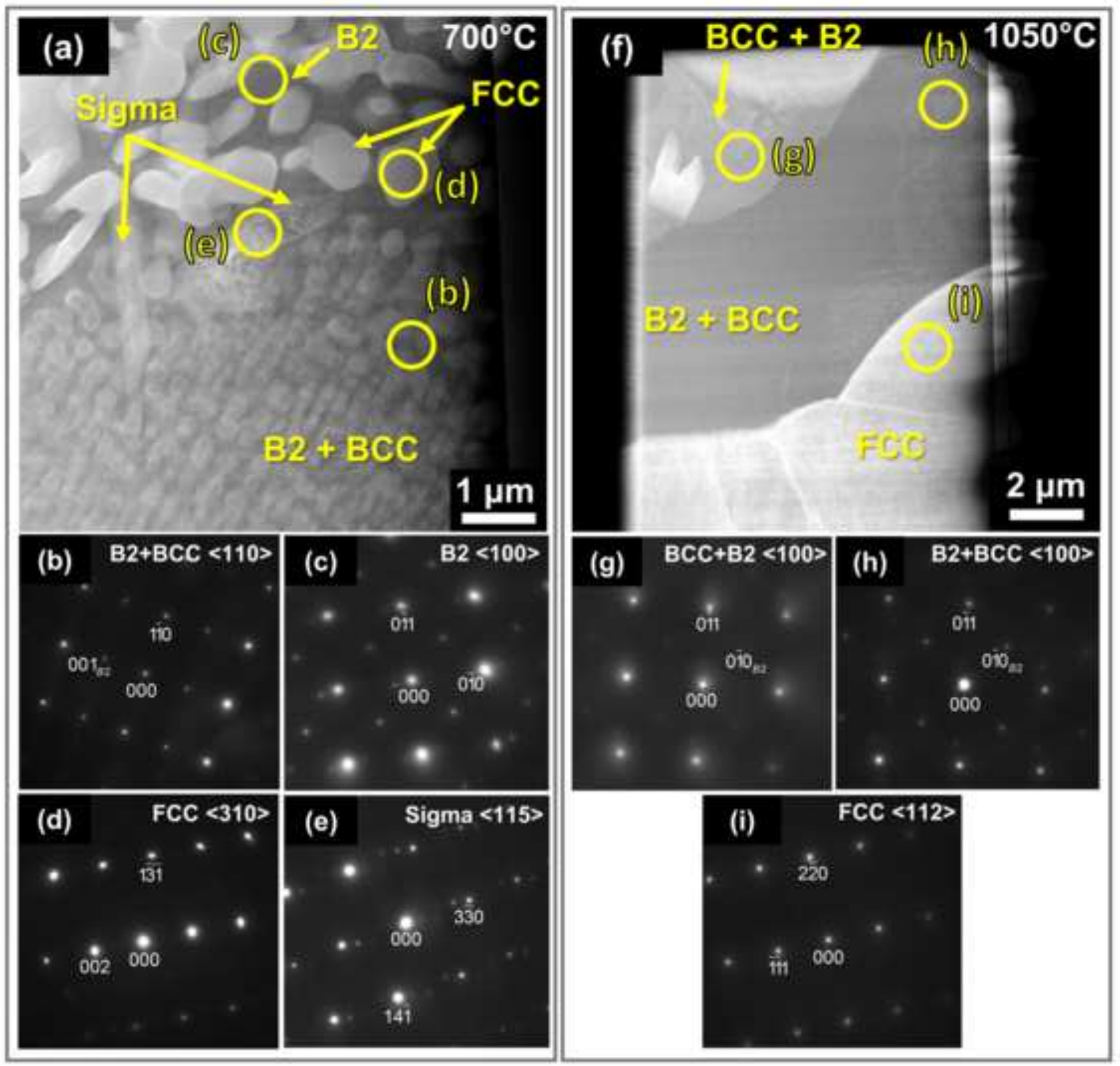



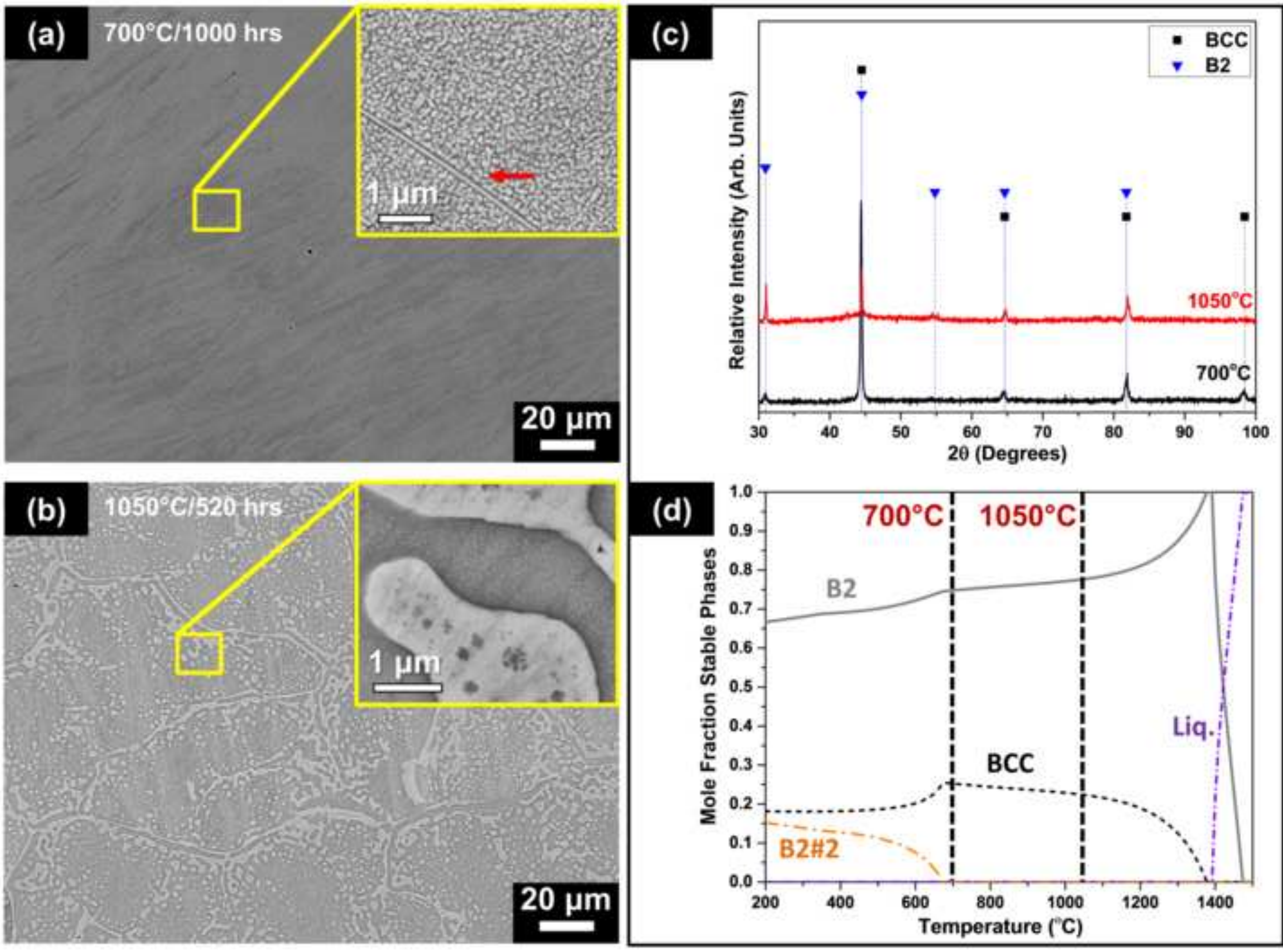


\section{(a)}

(1)

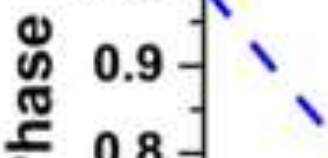

a

을 0.7

刃ำ 0.6

क 0.5

은 0.4

(는 0.3

it

$\frac{0}{5}$

0.2

0.1

0.0

\section{(b)}

Ð 0.9

ฮ $0.8-$

뜽 0.7 -

क

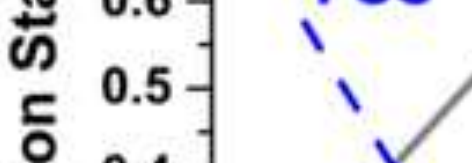

을
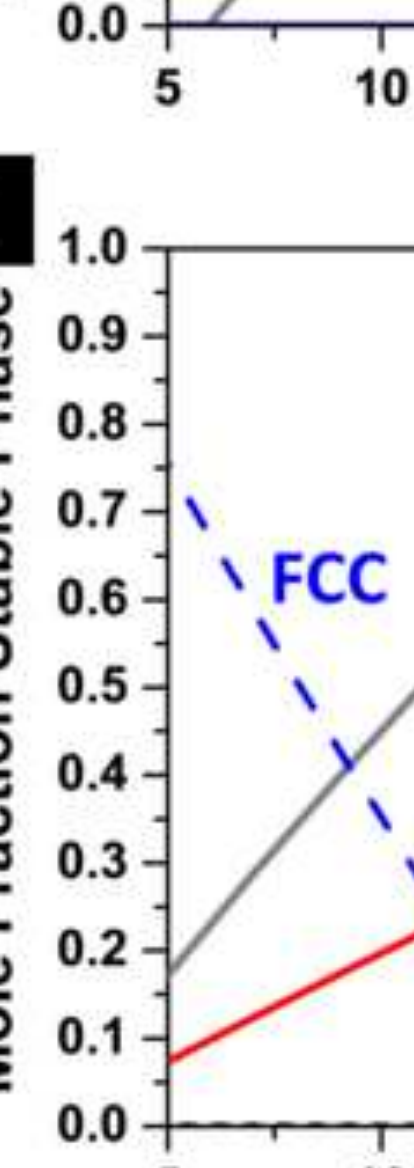

15

\section{B2}

$1050^{\circ} \mathrm{C}$

BCC

$\mathrm{Al}_{\mathrm{x}}(\mathrm{NiCoCrFe})_{100-\mathrm{x}}$ (at. \%)

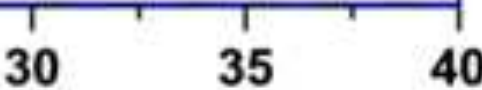

\section{B2}

Sigma

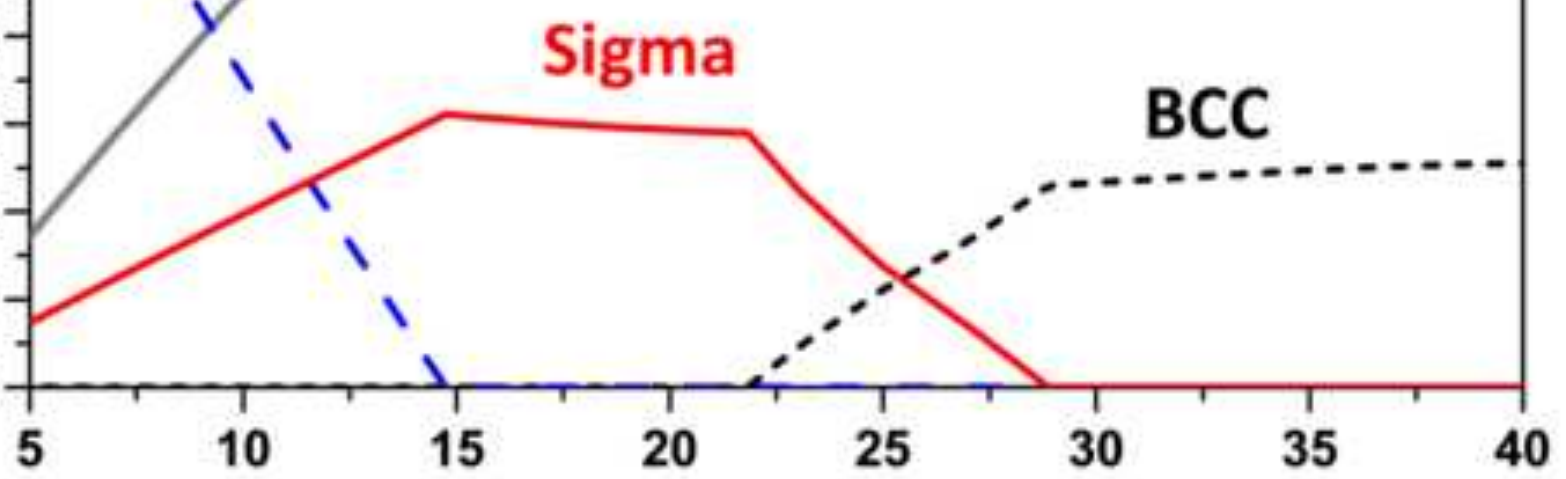

$\mathrm{Al}_{\mathrm{x}}(\mathrm{NiCoCrFe})_{100-x}$ (at. \%) 